\title{
INFORME*
}

\section{La STC 30/2011, de 16 de marzo, una sentencia decepcionante}

\section{INTRODUCGIÓN}

Antes que nada conviene dejar claro que la sentencia a que me refiero es una buena sentencia, podríamos decir que, incluso, es una sentencia técnicamente inobjetable, siempre que el criterio de enjuiciamiento sea un criterio formal, academicista, en el que valoremos por encima de todo el virtuosismo conceptual, el manejo de la dogmática jurídica, la perfección en el razonamiento sutil. Posiblemente muchas de las sentencias del Tribunal Constitucional que, al menos, una parte importante y en ocasiones mayoritaria de la opinión pública, hoy comúnmente denominada ciudadanía, no comparte suele encuadrarse en este tipo de sentencias. En mi opinión este fenómeno introduce un factor de tranquilización en la crítica. Se puede uno quedar tranquilo porque sabe que lo que le parece una enormidad puede no serlo, porque siempre habrá otros más avisados que él que lo comprenderán. Vayan por delante estas líneas para relativizar los términos de esta crítica que siempre podrán suavizarse apelando a la tosquedad de su autor.

\section{MI REPROCHE A LA SENTENCIA}

La sentencia en que el Tribunal Constitucional declara inconstitucional y, por tanto, anula el art. 51 de la Ley Orgánica 2/2007, de 19 de marzo, de reforma del Estatuto de autonomía para Andalucía, no puede considerarse mala, pero si decepcionante. Naturalmente que todas las sentencias son decepcionantes para la parte que pierde el litigio. En tal sentido es evidente que lo ha sido para algunos andaluces, como es comprensible la decepción de los sectores nacionalistas y allegados con la sentencia 30/2010, de 28 de junio. Sin embargo, no es ese tipo de decepción el que estoy glosando aquí. Me refiero a una

* La presente Sección ha sido elaborada bajo la dirección de José Ignacio MORILLO-VELARDE PÉREZ 
decepción objetiva que se vincula a la idea que, al menos a mí, me ha suscitado la sentencia, de que el pleito constitucional, y la sentencia por tanto, van por un lado y la realidad, por otro muy diferente. La lectura de la sentencia, cuando se tiene presente la ratio de la disposición discutida produce la sensación del agua -nunca mejor dicho- que se escapa por los vanos de una cesta de mimbre. Entre los sesudos y eruditos razonamientos de la sentencia apelando al principio de unidad de la nación española, la gestión racional y prudente de los recursos naturales, que parece solo puede garantizar Estado y la necesidad de que la gestión de las cuencas hidrográficas respete también el principio de unidad, el agua de la cuenca del Guadalquivir con sus características cuantitativas de extensión y reparto entre las diversas comunidades autónomas concernidas, aparece como una gran ausente. En efecto, si no fuera porque sabemos que el art. 51 del Estatuto de Andalucía se refiere al río Guadalquivir y a ocasionales menciones a este río y su cuenca en el texto de la sentencia, cualquiera diría que trata de cualquier río de los que atraviesan más de una comunidad autónoma, en definitiva, que lo que se afirma en la sentencia se puede predicar lo mismo del Guadalquivir que del Guadiana, el Ebro o el Tajo. Dicho de otra manera, que la competencia sobre las cuencas intercomunitarias corresponde al Estado, es algo que nadie ha dudado en ningún momento, por lo que es obvio que, en tanto que se da esta circunstancia, la del Guadalquivir debería seguir la misma suerte y así se ha entendido en la sentencia. Pero es evidente que esa no podía ser la cuestión, aunque a ello la hayan reducido la parte recurrente y el Tribunal. A esta conclusión se llega porque el cuerpo de la sentencia se ciñe a repetir los razonamientos que sirvieron en su día para rechazar la inconstitucionalidad de la ley de aguas de 1985 . No creo que esto lo haya cuestionado nadie ni en Andalucía ni desde Andalucía. Puesto que la cuenca del Guadalquivir excede el territorio de una comunidad autónoma -la andaluzala duda constitucional no podía ser si como tal, es decir, en cuanto productora de ese exceso, caía dentro de la competencia estatal sino más matizadamente, si puesto que ese exceso es cuantitativamente poco relevante para las restantes comunidades autónomas afectadas, pues hay que distribuirlo entre tres -Extremadura, recurrente, Murcia y Castilla-La Mancha- cabría una aplicación más benigna con aquella comunidad autónoma, siempre con las cautelas suficientes para las demás. Dicho de una forma más coloquial, si frente al todo o nada que parece haberse impuesto, cabría una interpretación más gradual y flexible de la Constitución que la consistente en su aplicación literal. De esta manera cabría la posibilidad de articular respuestas jurídicas variadas a una amplia pluralidad de situaciones: cuencas intracomunitarias, cuencas intercomunitarias y cuencas intercomunitarias de claro predominio de una comunidad autónoma. Con independencia de cual fuera la respuesta constitucional, creo que puede convenirse en que se recoge de esta manera mejor la realidad 
plural de las situaciones hídricas existentes en España que con el clásico dualismo de clara reminiscencia maniquea que, por lo que hemos visto, el Tribunal ha sido incapaz de superar. Es evidente que la literalidad del texto constitucional es la que es y también que en 1988 el Tribunal Constitucional hizo una meritoria labor interpretativa del mismo al enjuiciar la Ley de aguas de 1985, pero en este momento no se trataba de eso, que es lo que parece desprenderse de los fundamentos jurídicos de la sentencia que comento: ante el recurso de Extremadura el Tribunal espeta a Andalucía la doctrina sentada en la sentencia 227/1988.

La defensa de la Junta de Andalucía lo planteó muy correctamente, a mi juicio, cuando contraponía el interés regional como inspirador de los criterios del art. 148. 1 del texto constitucional con el criterio territorial del art. 149.1. 22. A su juicio, éste debía entrar en juego cuando quedara rebasado aquél, supuesto manifiestamente claro en cuencas intercomunitarias que todos tenemos presentes. Andalucía - y lo mismo podría decirse de Castilla y León con la cuenca del Duero- plantea un supuesto claramente diferenciado, intermedio entre las cuencas intracomunitarias e intercomunitarias, con una fisonomía tan propia como en su momento se pudo reconocer a aquéllas. Es la ausencia de ese posible criterio cuantitativo que matizase la aplicación del art. 149.1. 22 y su doctrina interpretativa -summum ius, summa iniuria- lo que pesa en la crítica de la sentencia. Si se me apura, no es a mi juicio criticable el que no se haya atendido el criterio a que aludo, sino el que apenas aparezcan referencias tangenciales al mismo. Así en el Antecedente 2, al relatar los argumentos del Gobierno de la Junta de Extremadura se alude a que dicho régimen pretendía justificarse en el carácter singular atribuido a la cuenca del Guadalquivir, siendo así que para el recurrente, ello no es un título habilitante que permita la atribución de competencias. Así es, en efecto, pero si es una circunstancia, un presupuesto fáctico que configura una determinada región y, por tanto, merece una cierta atención, aunque sea para desestimarlo no como título habilitante sino como circunstancia o hecho merecedor o no de un tratamiento específico. En eso consiste el reproche.

Interesa abundar algo más en los fundamentos del recurso del Consejo de Gobierno de Extremadura, al menos tal como los conozco a través de la propia sentencia pues considero que de alguna manera avalan lo que se viene diciendo aquí. Al margen del juicio que merezca el art. 149.1.22 CE, este ha de ser respetado en tanto no medie una reforma constitucional o una modificación del derecho comunitario, estando fuera los criterios de justicia material en los que a su juicio, parece apoyarse el consejo de Gobierno Consultivo andaluz. Se reconoce de esta manera alguna insuficiencia en el art. 149.1.22. Obviamente la consecuencia no puede ser su no acatamiento, pero si una interpretación apoyada justamente en esos criterios 
de justicia material que nadie se toma la molestia en desvirtuar. De eso es justamente de lo que se trata. Lo hizo el Parlamento de Andalucía y con posterioridad las Cortes Generales cuando aprobaron el art. 51 impugnado y debió hacerlo el Tribunal Constitucional, al menos para decir que no.

\section{LA POSICIÓN DE LA STC 30/2011}

La posición de la sentencia se desarrolla en su Fundamentos jurídicos 4 a 9 una vez rechazados los óbices procesales planteados por los órganos de la comunidad andaluza. El reproche fundamental que el Tribunal constitucional hace a la regulación contenida en el art. 51 debatido es que conduce a un entendimiento que acoge un modelo de gestión fragmentada de las aguas pertenecientes a una misma cuenca hidrográfica intercomunitaria, conforme a la cual una parte de la cuenca del Guadalquivir sería de la competencia exclusiva de la Comunidad Autónoma andaluza y otra parte de las aguas de esa misma cuenca sería de competencia del Estado. Pues claro, pero ese es el punto de partida, lo que hay que dilucidar: si se puede o no consentir ante las peculiares circunstancias y teniendo en cuenta que una cosa es la compartición competencial y otra muy distinta la fragmentación de la gestión. Es indudable que, al menos en principio, la exclusividad de la competencia debe favorecer la unidad de gestión, pero no puede sostenerse que la compartición competencial necesariamente suponga fragmentación de la gestión. Dicho de otra manera, el principio de unidad de cuenca no exige necesariamente la exclusividad competencial, pues existen mecanismos para lograr la unidad de gestión en esas circunstancias. La cuestión a debatir era precisamente si ante las razones que aportaba Andalucía se justificaba una matización o corrección del criterio literal del art. 149. 1. 22. La respuesta está implícita en tanto que el art. 51 del texto estatutario ha sido invalidado.

Pero no se hadado ninguna razón, porque no responde a dicha cuestión:

- que la norma constitucional permite referirse al conjunto integrado de las aguas de cada cuenca, que a través de corrientes principales y subalternas, trasvasan los confines del territorio de una comunidad autónoma (fundamento jurídico 5,-- Ya se sabía.

- que este Tribunal ha de tener en cuenta también el conjunto de los principios constitucionales de orden material que atañen, directa o indirectamente, a la ordenación y gestión de recursos naturales de tanta importancia como son los recursos hidráulicos, principios que, a modo de sintesis, se condensan en el mandato constitucional que obliga a todos los poderes públicos a velar por la "utilización racional de todos los recursos naturales" (art. 45.2 de la Constitución). Por ello, entre las diversas interpretaciones posibles de las reglas de distribución de competencias, este Tribunal sólo puede respaldar aquellas que razonablemente 
permitan cumplir dicho mandato y alcanzar los objetivos de protección y mejora de la calidad de vida y defensa y restauración del medio ambiente a los que aquél está inseparablemente vinculado. Nada que objetar con la pequeña matización aludida de que la compartición de competencias no tiene por qué afectar al principio de unidad de gestión, como la autonomía no afecta negativamente el principio de unidad nacional y siempre que no se entienda que el Estado es necesariamente mejor gestor de los recursos naturales que otros entes públicos o privados.

- que como corolario de lo anterior, en la citada STC 227/1988, realizamos una precisión que ahora se revela de la máxima importancia, al afirmar que la «expresión "aguas que discurran por más de una Comunidad Autónoma" es un concepto constitucional cuyo significado debe desentrañarse atendiendo a criterios lógicos, técnicos y de experiencia. Desde el punto de vista de la lógica de la gestión administrativa, no parece lo más razonable compartimentar el régimen jurídico y la administración de las aguas de cada curso fluvial y sus afluentes en atención a los confines geográficos de cada Comunidad Autónoma, pues es evidente que los usos y aprovechamientos que se realicen en el territorio de una de ellas condicionan las posibilidades de utilización de los caudales de los mismos cauces, principales y accesorios, cuando atraviesan el de otras Comunidades o surten a los cursos fluviales intercomunitarios

\section{CONCLUSIÓN}

Está muy claro que el art. 51 de la Ley Orgánica 2/2007, de 19 de marzo no es conforme con el criterio de interpretación que el Tribunal Constitucional asumió en su momentos -STC 227/1988, de 28 de noviembre- al enjuiciar la Ley de aguas de 1985. La sentencia 30/2011, de 16 de marzo no aporta novedad alguna al respecto. Me hubiera gustado una explicación más material y de fondo acerca de por qué no cabe una solución más ajustada a la realidad. 